Surg Clin North Am. 2011 August ; 91(4): 755-770. doi:10.1016/j.suc.2011.04.007.

\title{
Nutrition and Gut Immunity
}

\author{
Kazuhiko Fukatsu, MD, PhDa and Kenneth A Kudsk, MD \\ a Associate Professor, Surgical Center, The University of Tokyo Hospital, Tokyo, Japan \\ ${ }^{b}$ Professor of Surgery, Veterans Administration Surgical Services, William S. Middleton Memorial \\ Veterans Hospital and Department of Surgery, University of Wisconsin School of Medicine and \\ Public Health, Madison, Wisconsin
}

\section{Keywords}

phospholipase A2; gut associated lymphoid tissue; immunoglobulin A; glutamine; gut associated lymphoid tissue; mucosal immunity; enteral nutrition; parenteral nutrition

\section{Introduction}

The human intestine contains huge amounts of non pathologic bacteria surviving in an environment which is beneficial to both the host and the bacterial populations. In the normal, healthy individual, adequate nutrient intake and a normal environment provide a non-threatening environment for the bacteria which live in a symbiotic relationship in very close proximity to the intestinal mucosa. A number of barriers effectively keep the bacteria from entry into the systemic circulation. These barriers include mucus produced as a result of goblet cell secretion, as well as the presence of microbicidal and antiviral agents such as $a$ - defensins, cryptodins, lysozymes, and secretory phospholipase A2 (sPLA 2 ). These work together with the adaptive immune system that produces secretory $\operatorname{IgA}(\mathrm{sIgA})$, which provides a specific immune defense against the intraluminal bacteria. Although minor alterations in this symbiotic relationship may occur during minor stress, when short pauses in oral intake occur with minimal alterations in the mucosa/microbial interface, critical illness, with its attendant acidosis, prolonged GI tract starvation, exogenous antibiotics, and breakdown in mucosal defenses render the host vulnerable to bacterial challenge and also threaten the survival of the bacteria. Under these conditions, the bacteria face weakened host defenses while attempting to survive, rendering them hostile to the host. This review examines the altered innate and adaptive immunologic host defenses which occur as a result of altered oral or enteral intake and/or injury.

\section{Intact Defenses under Normal Conditions}

Physical barriers-A first line of defense against bacteria is the physical barrier which separates the bacteria from the systemic circulation. The intestinal epithelium consists of a single layer of columnar cells starting at the gastroesophageal junction and extending to the squamous epithelium of the anal canal. This physical barrier is selectively permeable and

\footnotetext{
(C) 2011 Elsevier Inc. All rights reserved.

Corresponding author; Kenneth A. Kudsk MD, 600 Highland Ave. G5/341, Madison, Wisconsin 53792, kudsk@surgery.wisc.edu, 608-263-1396.

Publisher's Disclaimer: This is a PDF file of an unedited manuscript that has been accepted for publication. As a service to our customers we are providing this early version of the manuscript. The manuscript will undergo copyediting, typesetting, and review of the resulting proof before it is published in its final citable form. Please note that during the production process errors may be discovered which could affect the content, and all legal disclaimers that apply to the journal pertain.
} 
capable of preventing transmigration of pathologic luminal substances from the external environment, i.e., the lumen, to the internal environment. The mucosal cells are closely bound to one another with filaments at both the basal and the apical portions of the cell to maintain normal polarity and tight junctions. Cell turnover occurs in an orderly fashion approximately every 5-7 days under the control of various factors, including epidermal growth factor, intestinal trefoil factor, et al. The mucosa is covered by micro-proteins in the form of mucin which coats their surface to create a physical barrier to the bacteria. The mucin contains high concentrations of defensins and other antibacterial molecules such as lactoferrin, lysozymes, and $\mathrm{sPLA}_{2} .{ }^{1} \mathrm{sPLA}_{2}$ destroys the integrity of the bacterial cell wall, while lactoferrin impairs the ability of bacteria to adhere to epithelial cells. ${ }^{1-2}$ Under conditions of severe stress and with alterations in normal oral intake, reductions in the mucin layer, impairment of the antimicrobial peptides in the mucin layer, and increased mucosal permeability to weaken this intrinsic defense and render it vulnerable to bacterial invasion.

Acquired Immunity-The mucosal immune system constitutes approximately 50-60 percent of the body's total immunity, producing about $7 \%$ of the antibody made by the body. ${ }^{3}$ It produces specific antibodies against intraluminal bacteria antibody in the form of secretory IgA (sIgA), which does not function through inflammation, but rather through adhesion and bacterial exclusion. Under normal conditions, antigen is sampled from the lumen after entry through specialized microvilli (M) cells, which cover Peyer's patches (Fig. 1). Dendritic cells within the Peyer's patches process the antigens and sensitize naive T \& B cells to these antigens. ${ }^{4}$ The sensitized $\mathrm{T} \& \mathrm{~B}$ cells then migrate to the mesenteric lymph nodes to mature and/or proliferate prior to their release into the thoracic duct. There they enter the systemic circulation to be distributed to submucosal sites in the upper and lower respiratory tract as well as the small and large intestine. In these sites, the influence of Th2 cytokines - IL-4, IL-5, IL-6, IL-10, and probably others - stimulate antibody production and transform the B cells into plasma cells capable of producing $\operatorname{IgM}$ and IgA for transport across the mucosa via a specialized transport mechanism. ${ }^{5}$ After release of dimeric IgA from the plasma cells, the IgA binds to molecules of polyimmune globulin receptor (pIgR) located on the basal surfaces of the mucosal cell. The mucosal cell transports this pIgR-IgA complex to the luminal surface where the IgA is released into the lumen. ${ }^{6,7} \mathrm{~A}$ small segment of $\mathrm{pIgR}$ (secretory component) remains attached to the $\operatorname{Ig} \mathrm{A}$, identifying it as $\operatorname{sg} \mathrm{A}$. Within the lumen, sIgA does not activate the complement system, but functions by binding to bacterial surface antigens to prevent or inhibit attachment of the bacteria to the mucosa. Preventing attachment precludes invasion by the bacteria. In both experimental and clinical work, alterations in diet and injury dramatically affect this coordinated system of acquired immunity in the respiratory and gastrointestinal tracts.

\section{The Clinical Correlates}

In the 1960's and 70's, a rapid growth in the use of parenteral nutrition occurred since it provided clinicians an avenue and method to provide adequate amounts of protein, carbohydrate, fat, electrolytes, trace elements, etc., to patients who otherwise starved due to loss of gut function. In the late 70's, experimental work suggested that benefits were gained when nutrients were delivered via the gastrointestinal tract which did not occur with IV feeding exclusively, when the gut was completely bypassed. ${ }^{8,9}$ Clinically, early studies of trauma patients noted that patients randomized either to starvation or to parenteral feeding had significant increases in rates of pneumonia and intra-abdominal abscess compared with patients who were fed directly into the intestine via jejunostomy. ${ }^{10-12}$ Subsequent studies on diverse patient populations confirmed this clinical effect. Several hypotheses, including the gut origin sepsis theory and the common mucosal immune hypothesis, have provided experimental data which provide cogent explanations for how enteral feeding maintains normal gut barrier function. 


\section{Mucosal immune changes with specialized nutrition support}

The common mucosal immune hypothesis provides a framework for mucosal immune maintenance, repopulation, and function. Specifically, T \& B cells, "educated" or sensitized at a specific mucosal site are distributed to other mucosal sites providing protection throughout the entire mucosal immune system. ${ }^{13}$ This occurs through a coordinated system of sensitization and distribution dependent upon cytokines, chemokines, adhesion molecules, and the ligands to those adhesion molecules.

Approximately $80 \%$ of circulating human and murine lymphocytes express $\alpha_{4} \beta_{7}$ and Lselectin, two molecules which identify these cells as destined for the mucosal immune system. ${ }^{14}$ As a result of eating, increased gastrointestinal tract blood flow stimulated by the dietary intake carries the naïve $\alpha_{4} \beta_{7}{ }^{+}$L-selectin ${ }^{+}$cells to their sites of sensitization, the Peyers patches. In both the lamina propria and the Peyer's patches, cells express mucosal address in adhesion molecule-1 (MAdCAM-1) a molecule which interacts with $\alpha_{4} \beta_{7}$ and Lselectin. In the Peyer's patches, MAdCAM-1 expressed in a modified form on the high endothelial venules, interacts vigorously with the cells expressing L-selectin, the predominating adhesion molecule expressed on naïve T\&B cells. ${ }^{15}$ After attachment, chemokines cause arrest and diapedesis of the T and B cells into the Peyer's patches. Chemokines are very small, soluble, tissue-specific proteins that activate cell signaling systems and increase integrin-cellular adhesion molecule binding. ${ }^{16-17}$ Overall, they stimulate chemotaxis. Within the Peyer's patches, the chemokine CCL21 regulates T cell entry while CXCL13 regulates B cell entry. Both play important roles in cell migration into the Peyer's patches, where the naive T and B cells become sensitized to antigens processed by the dendritic cells. This sensitization alters the cell surface molecule expression, which reduces expression of L-selectin, but increases expression of $\alpha_{4} \beta_{7}$. This alteration renders the cells more attractive to unmodified MAdCAM-1, which attract the sensitized T and B cells to sites of function within the submucosa in the lamina propria of the intestine as well as the lung and nasal passages. The B cells, under the influence of the sensitized T cells, switch into a plasma cell. The sensitized T cells release IgA-stimulating Th2 cytokines, which stimulate IgA production for eventual transport by $\mathrm{pIgR}$ into the lumen. ${ }^{18}$

This entire process appears integrated with stimulation of the gastrointestinal tract during enteral feeding. ${ }^{19}$ The gateway molecule for naïve B and T cells is MAdCAM-1, expressed on the HEV of the Peyer's patches. ${ }^{15}$ The administration of parenteral feeding (which relatively starves the gastrointestinal tract, but prevents malnutrition of the animals) results in a rapid down-regulation of MAdCAM-1 expression to approximately 50\% of normal levels and obstructs entry of naïve B and T cells into the mucosal immune system (Fig. 2). ${ }^{20}$ The role of MAdCAM-1 in this process is clearly demonstrated by administration of a blocking anti-MAdCAM antibody; blockade of MAdCAM-1 reproduces the effect of parenteral feeding. ${ }^{21}$ The proportion of T \& B cells within the Peyer's patches remains unchanged, but total cell numbers are reduced to approximately $40-50 \%$ of normal by 3 days. Simultaneously, cell levels drop in both the lung and intestinal lamina propria. MAdCAM-1 expression is stimulated by normal levels of IL-4 and stimulation of lymphotoxin $\beta$ receptor (LT $\beta R$ ) through interaction with activated T cells. ${ }^{22,23}$ Absence of enteral stimulation results in a significant drop in LT $\beta R$ levels in the Peyer's patches. Without activation of LT $\beta R$, levels of both MAdCAM-1 and IL4 drop due to impaired intracellular $\mathrm{NF \kappa B}$ activation.

In addition to the MAdCAM-1-related lymphocyte homing mechanism, gut immunity is controlled by Mitogen Activated Protein Kinase (MAPK) pathways, which play significant roles in mediating signals triggered by cytokines, growth factors, and environmental stress, and are involved in cell proliferation, cell differentiation, and cell death. Gut starvation blunts extracellular-regulated kinase (ERK) phosphorylation in effector sites of gut 
immunity, i.e., lamina propria and intraepithelial lymphocytes, in response to phorbol 12myristate 13-acetate (PMA) in vitro stimulation, while increased phosphorylation with PMA is observed in enteral feeding groups. ${ }^{24}$ In association with this change, lamina propria cell proliferation with PMA is reduced after parenteral feeding.

Within the lamina propria, significant changes occur in both IgA production and transport when the gut is starved. The lack of enteral feeding reduces levels of $\mathrm{T}$ regulatory cells, resulting in significant reductions in IL-4 and IL-10 levels, two important IgA-stimulating cytokines necessary for IgA production. ${ }^{18}$ Gut starvation also impairs IgA transport mechanisms through inhibition of the JAK-STAT signaling system, which maintains normal levels of pIgR. The combination of these changes results in impaired intestinal IgA production, a reduced transport of $\operatorname{IgA}$ into the lumen, and impairment of this defense mechanism. Surprisingly, lung pIgR levels are not affected during gut starvation and remain capable of transporting IgA produced by the underlying T and B cells. ${ }^{25}$ However, lung mechanisms are not completely intact since gut starvation reduces the absolute number of $\mathrm{T}$ and $\mathrm{B}$ cells within the lung, thus impairing mucosal immune function.

These changes impair both anti-viral and anti-bacterial defenses. Experimentally, murine defense against the H1N1 virus in the APR-8 mouse resides within IgA mediated immunity. ${ }^{26}$ If the H1N1 virus is administered intra-nasal to naïve mice, the mice will continue to shed virus from their nasal passages for 9-10 days until generation of adequate levels of IgA eliminate the infection. Immune mice then rapidly clear any subsequent doses of virus and sterilize the nasal passages if immunity remains intact. Animals fed via the gastrointestinal tract maintain this immunity: however, animals fed parentially lose this established immunity if challenged a second time with the virus. ${ }^{27}$ This impairment is functional and not due to loss of immunologic memory since two days of enteral feeding completely restores anti-viral immunity. A similar observation has been made in antibacterial defense against Pseudomonas in a pneumonia murine pneumonia model. ${ }^{28}$ Prior immunization with Pseudomonas antigen administered in liposomes reduces a $90 \%$ lethal model of intra-tracheal $P s$ to $10 \%$ mortality in enterally fed mice. However, the challenge is lethal to immunized animals fed parentally for 5 days.

Gut starvation also impairs the ability of animals to generate new immunity, a condition analogous to critically ill patients exposed to new bacterial challenge in ICUs. ${ }^{29}$ Normally, immunocytes specifically programmed to produce anti-H1N1 antibody begin to appear 6 days after naïve mice are initially exposed to the virus. Antiviral cells numbers peak around day 13. If the gut is starved during this time while the animals are fed parenterally, this process of cell programming and proliferation does not occur, and animals fail to generate immunity to the virus.

\section{Effect of route and type of nutrition on innate immune defense}

Unlike adaptive immunity, innate immunity recognizes and responds to organisms in a nonspecific system of defense. Paneth cells located at the base of crypts in the intestinal mucosa produce and release granules containing anti-microbial proteins and peptides into the lumen. These peptides which include lysozymes, $\mathrm{SPLA}_{2}$, and defensins are conserved components of innate immune responses found at all evolutionary levels of plants and animals. For example, $\mathrm{SPLA}_{2}$ is an enzyme that is expressed in many cell types and in various bodily fluids. It functions as a pro-inflammatory enzyme in tissues to activate neutrophils within the circulatory system, but it serves an anti-bacterial function within the lumen of the intestine by binding to the bacterial cell wall and killing the microbe via phospholipolytic enzyme activity. ${ }^{1}$ Gut starvation during parenteral nutrition influences the innate system, resulting in significant drops in the levels of $\mathrm{SPA}_{2}$ within the intestinal secretions. The 
$\mathrm{SPLA}_{2}$ that is present in parenterally fed mice is less bactericidal than $\mathrm{SPLA}_{2}$ obtained from enterally fed mice at equal molar concentrations.

\section{The effects of nutrition on response to injury}

Critically ill patients requiring nutrition support have sustained injury whether it is trauma related or related to the stress and injury of surgery. Experimentally, the route of nutrition affects the inflammatory response generated by both the innate and the adaptive immunity.

Effects of injury on systemic inflammation-Disproportionate splanchnic hypoperfusion, a common feature of shock and trauma, is considered to be an important factor in multiple organ failure (MOF). Gut hypoxia directly injures gut morphological structure, rendering gut barrier function compromised and allowing translocation of bacteria and toxins in gut lumen

Alterations in cytokines due to gut starvation affect both the mucosal immune system and systemic inflammatory responses. The lamina propria contains large numbers of blood vessels which respond to the changes in cytokines and alter endothelial adhesion molecule expression. ${ }^{30}$ As discussed above, IL-4 and IL-10 levels drop in the lamina propria during gut starvation and parenteral feeding; no changes occurs in the Th1 cytokine, interferon gamma (IFN $\gamma$ ). ${ }^{11,31}$ These 3 cytokines influence expression of vascular endothelial molecules. Normal levels of IL-4 and IL-10 suppress expression of intracellular adhesion molecule-1 (ICAM-1), a molecule which attracts neutrophils to the vascular endothelium leading to their attachment. ${ }^{30}$ IFN $\gamma$ however stimulates expression of ICAM-1. Normally, the opposing influences of the Th1 and Th2 cytokines maintain homeostasis and controlled activation of neutrophils. However, as gut starvation reduces IL-4 and Il- 10, endothelial ICAM-1 expression increases within the small intestine, and neutrophils accumulate in the tissues. This is significant since the gut is capable of priming neutrophils to subsequent injury. ${ }^{32}$ This priming occurs though interaction between tissue priming signals, such as sPLA $_{2}$ and the accumulated neutrophils, which then are released from the gut and distributed to other sites such as the lung and liver. In these sites the primed neutrophils generate an exaggerated inflammatory response to subsequent injury. Gut starvation with parenteral nutrition increases ICAM-1, and neutrophils accumulate within the small intestine and are primed. Their priming is evident since relatively short episodes of gut ischemia and reperfusion produces an intense inflammatory response in the lung and liver in association with increased expression of CD11B and CD18 on circulating and tissue bound cells, respectively. ${ }^{32}$ The ultimate result is an increase in the mortality rate of parenterally fed mice after gut ischemia and reperfusion with increases in both liver and lung permeability and edema. ${ }^{33}$ A kinetic study of gut immunity after severe gut ischemia-reperfusion in mice clarified an important mechanism for poor outcome after injury. Gut ischemia-reperfusion caused rapid and prolonged reduction of gut associated lymphoid tissue cell lymphocytes, particularly in intraepithelial space and lamina propria. Interestingly, administration of an oral intake of diet after gut ischemia-reperfusion, normally a potent stimulant for gut immunity recovery, resulted in marked gut associated lymphoid tissue (GALT) atrophy as long as day 7 after injury.

The relevance of this augmented response to critically injured patients is just now becoming evident. Studies of trauma patients undergoing bronchoalveolar lavage (BAL) show acute increases in airway IgA along with the increased levels TNF $\alpha$, IL-1b and IL-6 within BAL specimens. ${ }^{34,35}$ A similar response occurs in the airways of mice 8 hours after a controlled surgical injury; IgA levels increase in concert with elevated TNF- $\alpha$, IL- $1 \beta$ and IL- 6 in BAL specimens. Clearly, these cytokines are involved since administration of anti-TNF or anti 
IL-1 $\beta$ monoclonal antibodies eliminate the airway IgA response in the mice. ${ }^{36}$ This IgA response to injury is also eliminated after gut starvation and parenteral nutrition.

Effects of diet on innate immune responses to injury- $\mathrm{SLAA}_{2}$ regulates a cosmetic production within a gut wall and appears to be the factor which primes neutrophils after their attachment to the gut wall during hemorrhagic shock or parenteral nutrition. $\mathrm{sLA}_{2}$ activity within the lumen is bactericidal. $\mathrm{SPLA}_{2}$ is a family of lipolytic enzymes which hydrolyze phospholipids to release long chain fatty acids from bacterial membranes. In vitro, $\mathrm{sPLA}_{2}$ IIa kills gram positive and some gram negative bacterial species ${ }^{37-40}$; over expression of sPLA $_{2}$-IIa in transgenic mice reduces their susceptibility to sepsis during bacterial challenge. ${ }^{41}$ Parenteral nutrition with gut starvation reduces the activity of $\mathrm{SPLA}_{2}$ in intestinal fluid. This reduction is associated with an impaired bactericidal activity due to reduced absolute amounts of SPLA $_{2}$ in the fluid as well as production of a less active form of the enzyme. Surprisingly, injury reduces levels of $\mathrm{SPLA}_{2}$ to levels comparable to parenterally fed animals. This may be a protective mechanism since high levels of luminal $\mathrm{SPLA}_{2}$ can attack not only the bacteria, but also the mucosa in the presence of increased mucosal permeability. However, enterally fed animals increased levels of intestinal IgA in response to the injury, which may serve to neutralize bacteria within the lumen. Gut starvation with parenteral feeding does not increase intestinal (or lung) IgA, denoting a failure in both innate and acquired mucosal immunity. ${ }^{42}$

\section{Exogenous support of diet-related impairment of gut immunity (Table 1)}

Neuropeptides-The intestine is infiltrated with approximately 3 meters of nerve for every cubic millimeter of tissue, with most on this nervous tissue located in and around the GALT. These fibers release a number of neuropeptides, including gastrin releasing peptide (GRP), neurotensin, cholecystokinin, et al. GRP is one of the first peptides released during eating, and it stimulates the release of other neuropeptides throughout the intestine, including gastrin. ${ }^{43}$ Experimentally, the peptide, bombesin (BBS), has been used to study GRP effects since both share the same 7 amino acid sequence which provides their function. Parenteral feeding supplemented with BBS prevents the reduced cell numbers within the Peyer's patches and the lamina propria, normalizes the Th2 cytokine levels, maintains both respiratory and intestinal IgA levels, and reverses the defect in anti-bacterial and anti-viral defenses noted in parenterally fed mice. ${ }^{43,44,45,46}$ BBS has no effect on MAdCAM-1 and probably works via direct cell effects. It provides no protective effect after gut ischemia with reperfusion. However, it warrants further investigation as a tool to improve respiratory immunity in patients who are unable to be fed via the gastrointestinal tract.

Glutamine-Glutamine is the most abundant free amino acid within the body, and since it can be synthesized by the body, is not considered an essential amino acid in health. However, during prolonged, severe stress, production in tissues fails to meet the systemic demands, and glutamine becomes "conditionally essential." It is not a usual component of commercial amino acid components of parenteral nutrition since heat sterilization converts the molecule into pyroglutamate, a toxic substance. However, glutamine can be added to parenteral nutrition prior to filter sterilization. Glutamine supplementation improves mucosal immunity by increasing the number of lymphocytes in the Peyer's patches and the lamina propria, partially normalizes tissue $\mathrm{TH} 2$ cytokine levels, and improves respiratory and intestinal IgA levels, but not to levels maintained in chow fed mice. ${ }^{47,48,49}$ Glutamine also improves, but does not normalize, the anti-bacterial and anti-viral defenses. ${ }^{47,50}$ Interestingly, it completely reverses the increase in mortality of parenterally fed mice after gut ischemia and reperfusion. ${ }^{51}$ It does not work through MAdCAM-1, which remains unchanged from parenteral levels. ${ }^{52}$ Currently, several clinical studies suggest an 
improvement in infectious complications with glutamine supplemented parenteral nutrition, and larger clinical trials are underway.

Butyric acid-Dietary carbohydrates escaping digestion/absorption in the small intestine and prebiotics undergo fermentation in the colon to give rise to short-chain fatty acids (SCFAs) ${ }^{53}$ Butyric acid, a SCFA, provides a significant source of calories exerting trophic effects on both the small and large intestines ${ }^{54,55}$ Parenteral administration of butyric acid reportedly reverses parenteral nutrition-induced gut atrophy. ${ }^{56}$ Partial replacement of acetic acid (which is added for $\mathrm{pH}$ adjustment to parenteral nutrition solution) by butyric acid moderately improved Peyer's patch lymphocyte number and IgA levels in small intestine and bronchoalveolar washings of parenterally fed animals, but the mechanism underlying the immune changes remains unclear ${ }^{57}$.

Interleukin-7-The immune processes in gut associated lymphoid tissue are mediated by various cytokine-receptor pathways. Interleukin-7 (IL-7) produced by intestinal epithelial cells appears particularly important because of its pleiotropic functions. ${ }^{58}$ Epithelial cellderived IL-7 and its receptor (IL-7R) contribute to the development and activation of intraepithelial $\gamma \delta \mathrm{T}$ cells and prevents spontaneous apoptosis of $\gamma \delta$ and $\alpha \beta$ IE lymphocytes by inhibiting caspase dependent and independent pathways. ${ }^{59} \mathrm{IL}-7$ also plays a role in the proliferation and function of IE, LP, and PP lymphocytes. ${ }^{60} \mathrm{PN}$ decreases intestinal epithelial cell-derived IL-7 mRNA expression, while exogenous IL-7 during PN restores lymphocyte numbers in Peyer's patches, the intraepithelial space, and lamina propria, but has no effect on IgA levels. ${ }^{61-63}$ Exogenous IL-7 administration also improved survival in a gut derived sepsis model induced by gavage administration of live Pseudomonas.

\section{Influences of chemotherapy insults on gut immunity}

Chemotherapy-induced intestinal injury induces morphological changes in the gastrointestinal tract while certain anti-cancer drugs impair gut immunity. Continuous infusion of 5-fluorouracil (5FU), a fluorinated pyrimidine, reduces gut associated lymphoid tissue mass and secretory $\operatorname{IgA}$ levels in a murine model without reducing oral intake or creating other gastrointestinal symptoms ${ }^{64}$ Concomitant enteral infusion of fish oil as a source of omega 3 fatty acids restored intraepithelial and lamina propria lymphocyte numbers and bronchoalveolar IgA levels to control group levels, while fish oil added to PN had no beneficial effects on PN-induced atrophy of gut associated lymphoid tissue. ${ }^{65,66}$ Since omega 3 fatty acids reportedly have the property to enhance sensitivity of certain tumor cells to chemotherapy, ${ }^{67}$ combination therapy using anti-cancer drugs and omega 3 fatty acids could provide a therapeutic tool to enhance anticancer effects and decrease infectious complications.

\section{Peritoneal Defenses}

Clinical studies of trauma patients demonstrated that parenteral feeding resulted in significant increases in intra-abdominal abscess compared with enteral feeding. ${ }^{10-12}$ Experimental work demonstrates that gut starvation affects peritoneal host defense against bacterial contamination as well as gut and repiratory mucosal immunity.

Several host defense mechanisms come into play early after bacterial contamination of the peritoneal cavity. ${ }^{68}$ Peritonitis activates peritoneal resident macrophages to produce proinflammatory cytokines and chemokines. These macrophages phagocytize and kill bacteria, while secreted mediators stimulate massive influx of neutrophils into the peritoneal cavity. The exudative neutrophils eliminate microbes by releasing oxygen products and enzymes. In addition, diaphragmatic lymphatics clear bacteria from the peritoneal cavity. 
This appropriate activation of peritoneal resident and exudative leukocytes in response to peritoneal contamination appears to be essential for preventing intra-abdominal abscess.

$\mathrm{NF \kappa B}$ is a key ubiquitous transcription factor increasing gene expressions of proinflammatory cytokines, growth factors, chemokines, and adhesion molecules. ${ }^{69} \mathrm{NF \kappa B}$ resides in the cytoplasm in an inactive form as a heterodimer consisting of p50 and RelA

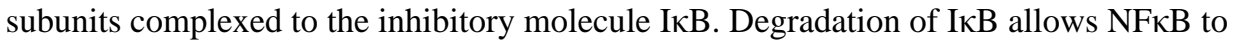
translocate to the nucleus and bind to its specific DNA site. Work using laser scanning cytometer clarified that gut starvation inhibits NF $\kappa B$ translocation in peritoneal resident macrophages and exudative neutrophils even when the animals receive sufficient nutrients parenterally (Fig. 3) ${ }^{70,71}$ The blunted NFkB activation in parenterally fed animals resulted in delayed increases in peritoneal pro-inflammatory and anti-inflammatory cytokines as well as the levels of chemokine, MIP-2. An impaired peritoneal defense was confirmed using a cecal ligation and puncture (CLP)-induced peritonitis model to mimic clinical peritonitis due to bacterial contamination and necrotic tissue. Absence of enteral feeding significantly reduced survival time compared with enteral feeding the animals.

Specialized parenteral formulas designed to maintain peritoneal host defense have been investigated. An arginine-enriched (1\% arginine) parenteral formula restored $\mathrm{NF \kappa B}$ activation in peritoneal resident and exudative leukocytes as well as the intraperitoneal cytokine response, leading to improved survival after cecal ligation and puncture, compared with standard parenteral formulas containing $0.3 \%$ arginine. ${ }^{72}$ An alanyl-glutaminesupplemented parenteral formula also enhanced TNF $\alpha$ levels in peritoneal cavity as well as liver and splenic IFN $\gamma$ levels after intraperitoneal injection of live E. coli. ${ }^{73}$ The formula also reduced IL-8 levels and the number of bacteria isolated from systemic blood samples. This finding suggests that glutamine augments peritoneal defenses to minimize bacterial dissemination into the systemic circulation. This does not appear to be due to normalization of NFKB activation.

\section{Hepatic Immunity}

Parenteral nutrition induces hepatic-steatosis, decreases bile flow and hepatic secretory function, and impairs albumin synthesis and drug conjugation. Gut starvation also influences hepatic immunity.

The liver plays an important role in the innate immune response, providing a first line of defense against intestinal microbes and toxins crossing the intestinal barrier. The liver contains a significant number of mononuclear cells (MNCs) including Kupffer cells, resident hepatic macrophages (which constantly clear bacteria and toxins from the peripheral circulation), resident and liver-infiltrating natural killer cells, and T and B cells. ${ }^{74}$ When activated with bacterial endotoxin, Kupffer cells produce proinflammatory cytokines and clear pathogens by phagocytosis. Therefore, the liver plays a central role in immunity, responding to, and eliminating, pathogenic microorganisms and toxins.

Gut starvation reduces hepatic MNC number to approximately $50 \%$ of chow-fed levels. ${ }^{75}$ Parenterally fed mice express lower levels of the lipopolysaccharide (LPS) receptors, CD14 and TLR-4, on cell membrane compared with enteral feeding, leading to a lower ERK phosphorylation response to LPS stimulation. Hepatic MNCs after parenteral feeding do not increase TNF $\alpha$, IFN $\gamma$ or IL-10 production when cultured in vitro with LPS, while hepatic MNCs after enteral feeding remain capable of dose dependent increases in cytokine production following LPS. Deranged function of the hepatic MNC system during gut starvation may allow systemic dissemination of bacteria and toxins, which have crossed the gut barrier and enter the portal circulation. Parenteral feeding significantly worsens survival after injection of Pseudomonas aeruginosa into the portal vein. 
Dietary alteration in hepatic immunity may be partly explained through changes in portal blood flow. ${ }^{76,77}$ Twelve hours of chow feeding almost completely restores gut starvationinduced reduction in hepatic MNC numbers to normal levels in mice. Simultaneously, blood flow in the small intestine and portal vein fully recovers to normal levels. A positive correlation exists between portal vein blood flow and hepatic MNC number. Intravenous administration of prostaglandin $\mathrm{E}_{1}$, a potent enhancer of portal vein blood flow, significantly restores hepatic MNC number during fasting, confirming that increase in portal blood flow is important for maintenance of hepatic immunity.

\section{Summary}

Gut starvation impairs intestinal and extra-intestinal mucosal immunity via changes in mucosal associated lymphoid tissue mass and function. Gut starvation also affects extraintestinal non-mucosal immunity, including peritoneal host defense and hepatic MNCs (Fig. 4). Key features of these changes are: 1) reduction of immune cells in local sites, and 2) hypo-responsiveness of immune cells to stimulation. Excessive inflammatory response following severe insults has been discussed with special emphasis on mechanisms underlying tissue injury and multiple organ failure. Preventing excessive inflammation is one goal when treating severely injured and/or critically ill patients. Nutrition, particularly route and quality of nutrient delivery, affects the integrity of the entire host defense system.

\section{References}

1. Beers SA, Buckland AG, Koduri RS, et al. The antibacterial properties of secreted phospholipase A2: a major physiological role for the group IIA enzyme that depends on the very high $\mathrm{pI}$ of the enzyme to allow penetration of the bacterial cell wall. Jour Biol Chem. 2002; 277:1788-1793. [PubMed: 11706041]

2. Koduri RS, Gronroos JO, Laine VJO, et al. Bacteridical properties of human and murine groups I, II, V, X, and XII secreted phospholipases A2. Jour biol chem. 2002; 277:5849-5857. [PubMed: 11694541]

3. McGhee JR, Mestecky J, Dertzbaugh MT, et al. The mucosal immune system: from fundamental concepts to vaccine development. Vaccine. 1992; 10:75-88. [PubMed: 1539467]

4. Guy-Grand D, Griscelli C, Vassalli P. The gut-associated lymphoid system: nature and properties of the large dividing cells. Eur J Immunol. 1974; 4:435-443. [PubMed: 4213445]

5. Roux ME, McWilliams M, Phillips-Quagliata JM, et al. Differentiation pathway of Peyer's patch precursors of IgA plasma cells in the secretory immune system. Cell Immunol. 1981; 61:141-153. [PubMed: 7196290]

6. Kaetzel CS. The polymeric immunoglobulin receptor: bridging innate and adaptive immune responses at mucosal surfaces. Immunologic Reviews. 2005; 206:83-99.

7. Mostov KE, Friedlander M, Blobel G. The receptor for transepithelial transport of IgA and IgM contains multiple immunoglobulin-like domains. Nature. 1984; 308:37-43. [PubMed: 6322002]

8. Kudsk KA, Carpenter BS, Peterson S, et al. Effect of Enteral and Parenteral Feeding in Malnourished Rats with E. coli-Hemoglobin Adjuvant Peritonitis. J Surg Res. 1981; 31:105-110. [PubMed: 6790873]

9. Kudsk KA, Stone JM, Carpenter BA, et al. Enteral and parenteral feeding influences mortality after hemoglobin-E. coli peritonitis in normal rats. J Trauma. 1983; 23:605-609. [PubMed: 6410081]

10. Moore FA, Moore EE, Jones TN, et al. TEN versus TPN following major abdominal traumareduced septic morbidity. J Trauma. 1989; 29:916-923. [PubMed: 2501509]

11. Moore EE, Jones TN. Benefits of immediate jejunostomy feeding after major abdominal trauma--a prospective, randomized study. J Trauma. 1986; 26:874-881. [PubMed: 3095557]

12. Kudsk KA, Croce MA, Fabian TC, et al. Enteral vs. parenteral feeding: Effects on septic morbidity following blunt and penetrating abdominal trauma. Ann Surg. 1992; 215(5):503-513. [PubMed: 1616387] 
13. Czerkinsky C, Prince SJ, Michalek SM, et al. IgA antibody-producing cells in peripheral blood after antigen ingestion: evidence for a common mucosal immune system in humans. Proc Natl Acad Sci U S A. 1987; 84:2449-2453. [PubMed: 3470804]

14. Bargatze RF, Jutila MA, Butcher EC. Distinct roles of L-selectin and integrins alpha 4 beta 7 and LFA-1 in lymphocyte homing to Peyer's patch-HEV in situ: the multistep model confirmed and refined. Immunity. 1995; 3:99-108. [PubMed: 7542550]

15. Sikorski EE, Hallmann R, Berg EL, et al. The Peyer's patch high endothelial receptor for lymphocytes, the mucosal vascular addressin, is induced on a murine endothelial cell line by tumor necrosis factor- $\alpha$ and IL-1. J Immunol. 1993; 151:5239-5250. [PubMed: 7693807]

16. Campbell JJ, Hedrick J, Zlotnik A, et al. Chemokines and the arrest of lymphocytes rolling under flow conditions. Science. 1998; 279:381-384. [PubMed: 9430588]

17. Laudanna C, Kim JY, Constantin G, et al. Rapid leukocyte integrin activation by chemokines. Immunol Rev. 2002; 186:37-46. [PubMed: 12234360]

18. Wu Y, Kudsk KA, DeWitt RC, et al. Route and type of nutrition influence IgA-mediated intestinal cytokines. Ann Surg. 1999; 229:662-668. [PubMed: 10235524]

19. Kudsk KA. 2008 Rhoads Lecture: Of mice and men......and a few hundred rats. J Parenter Enteral Nutr. 2008; 32(4):460-473.

20. Zarzaur BL, Fukatsu K, Johnson CJ, et al. A temporal study of diet-induced changes in peyer patch MAdCAM-1 expression. Surgical Forum. 2001; 52:194-196.

21. Ikeda S, Kudsk KA, Fukatsu K, et al. Enteral Feeding Preserves Mucosal Immunity Despite in vivo MAdCAM-1 Blockage of Lymphocyte Homing. Ann Surg. 2003; 237(5):677-685. [PubMed: 12724634]

22. Kang W, Gomez EF, Lan J, et al. Parenteral Nutrition (PN) Impairs Gut-associated Lymphoid Tissue (GALT) and Mucosal Immunity by Reducing Lymphotoxin $\beta$ Receptor (LT $\beta$ R)

Expression. Ann Surg. 2006; 244(3):392-399. [PubMed: 16926565]

23. Kang W, Kudsk KA, Sano Y, et al. Effects of Lymphotoxin $\beta$ Receptor Blockade on Intestinal Mucosal Immunity. JPEN. 2007; 31(5):358-365.

24. Maeshima Y, Fukatsu K, Kang W, et al. Lack of enteral nutrition blunts extracellular regulated kinase phosphorylation in gut-associated lymphoid tissue. Shock. 2007; 27(3):320-325. [PubMed: 17304114]

25. Kudsk KA, Gomez FE, Kang W, et al. Enteral feeding of a chemically-defined diet preserves pulmonary immunity but not intestinal immunity: the role of lymphotoxin beta receptor (LT $\beta R$ ). J Parenter Enteral Nutr. 2007; 31(6):477-481.

26. Renegar KB, Johnson C, DeWitt RC, et al. Impairment of mucosal immunity by total parenteral nutrition (TPN): Requirement for IgA in murine nasotracheal anti-influenza immunity. J Immunol. 2001; 166:819-825. [PubMed: 11145655]

27. Kudsk KA, Li J, Renegar KB. Loss of upper respiratory tract immunity with parenteral feeding. Ann Surg. 1996; 223(6):629-638. [PubMed: 8645036]

28. King BK, Kudsk KA, Li J, et al. Route and type of nutrition influence mucosal immunity to bacterial pneumonia. Ann Surg. 1999; 229(2):272-278. [PubMed: 10024110]

29. Johnson CD, Kudsk KA, Fukatsu K, et al. Route of nutrition influences generation of antibodyforming cells (AFCs) and initial defense to an active viral infection in the upper respiratory tract. Ann Surg. 2003; (4):565-573. [PubMed: 12677154]

30. Fukatsu K, Lundberg AH, Hanna MK, et al. Route of nutrition influences intercellular adhesion molecule-1 expression and neutrophil accumulation in intestine. Arch Surg. 1999; 134:1055-1060. [PubMed: 10522845]

31. Fukatsu K, Kudsk KA, Wu Y, et al. TPN decreases IL-4 and IL-10 mRNA expression in lamina propria cells but glutamine supplementation preserves the expression. Shock. 2001; 15(4):318322. [PubMed: 11303733]

32. Fukatsu K, Kudsk KA, Zarzaur BL, et al. Increased ICAM-1 and $\beta 2$ integrin expression in parenterally fed mice after a gut ischemic insult. Shock. 2002; 18(2):119-24. [PubMed: 12166773]

33. Fukatsu K, Zarzaur BL, Johnson CD, et al. Enteral nutrition prevents remote organ injury and mortality following a gut ischemic insult. Ann Surg. 2001; 233(5):660-668. [PubMed: 11323505]

Surg Clin North Am. Author manuscript; available in PMC 2012 August 1. 
34. Kudsk KA, Hermsen JL, Genton L, et al. Injury stimulates an innate respiratory IgA immune response in humans. J Trauma. 2008; 64(2):316-325. [PubMed: 18301193]

35. Jonker MA, Hermsen JL, Gomez FE, et al. Injury Induces Localized Airway Increases in ProInflammatory Cytokines in Humans and Mice Surg Infections. in press.

36. Hermsen JL, Sano Y, Gomez FE, et al. Parenteral Nutrition Inhibits a Tumor Necrosis Factor- $\alpha$ Mediated IgA Response to Injury. Surgical Infections (Larchmt). 2008; 9(1):33-40.

37. Weinrauch Y, Elsbach, Madsen LM, et al. The potent anti-Staphylococcus aureus activity of a sterile rabbit inflammatory fluid is due to a 14-kD phospholipase A2. J Clin Invest. 1996 Jan 1; 97(1):250-7. [PubMed: 8550843]

38. Weinrauch Y, Abad C, Liang NS, et al. Mobilization of potent plasma bactericidal activity during systemic bacterial challenge. Role of group IIA phospholipase A2. J Clin Invest. 1998; 102(3): 633-8. [PubMed: 9691100]

39. Harwig SS, Tan L, Qu XD, et al. Bactericidal properties of murine intestinal phospholipase A2. J Clin Invest. 1995; 95(2):603-10. [PubMed: 7860744]

40. Weiss J, Inada M, Elsbach P, et al. Structural determinants of the action against Escherichia coli of a human inflammatory fluid phospholipase A2 in concert with polymorphonuclear leukocytes. Biol Chem. 1994; 269(42):26331-7.

41. Laine VJ, Grass DS, Nevalainen TJ. Protection by Group II Phospholipase A2 against Staohylococcus aureus. Jour of Immunology. 1999; 162:7402-7408. [PubMed: 10358193]

42. Sano Y, Hermsen JL, Kang K, et al. Parenteral nutrition maintains pulmonary IgA antibody transport capacity, but not active transport, following injury. Am J Surg. 2009; 198(1):105-109. [PubMed: 19249732]

43. Li J, Kudsk KA, Hamidian M, et al. Bombesin affects mucosal immunity and gut-associated lymphoid tissue in IV-fed mice. Arch Surg. 1995; 130:1164-1170. [PubMed: 7487458]

44. Janu P, Kudsk KA, Li J, et al. Effect of bombesin on impairment of upper respiratory tract immunity induced by total parenteral nutrition. Arch Surg. 1997; 132:89-93. [PubMed: 9006558]

45. DeWitt RC, Wu Y, Renegar KB, et al. Bombesin recovers gut-associated lymphoid tissue (GALT) and preserves immunity to bacterial pneumonia in TPN-fed mice. Ann Surg. 2000; 231(1):1-8. [PubMed: 10636095]

46. Hanna MK, Zarzaur BL, Fukatsu K, et al. Individual neuropeptides regulate gut-associated lymphoid tissue integrity, intestinal IgA levels, and respiratory antibacterial immunity. J Parenter Enteral Nutr. 2000; 24(5):261-269.

47. Li J, Kudsk KA, Janu P, et al. Effect of glutamine-enriched TPN on small intestine gut-associated lymphoid tissue (GALT) and upper respiratory tract immunity. Surgery. 1997; 121(5):542-549. [PubMed: 9142153]

48. Li J, King KA, Janu PG, et al. Glycyl-L-glutamine-enriched total parenteral nutrition maintains small intestine gut-associated lymphoid tissue and upper respiratory tract immunity. J Parenter Enteral Nutr. 1998; 22(1):31-36.

49. Kudsk KA, Wu Y, Fukatsu K, et al. Glutamine-enriched total parenteral nutrition maintains intestinal interleukin-4 and mucosal immunoglobulin A levels. J Parenter Enteral Nutr. 2000; 24(5):270-275.

50. DeWitt RC, Wu Y, Renegar KB, et al. Glutamine-enriched TPN preserves respiratory immunity and improves survival to a Pseudomonas pneumonia. J Surg Res. 1999; 84:13-18. [PubMed: 10334882]

51. Ikeda S, Zarzaur BL, Johnson CD, et al. Total parenteral nutrition supplementation with glutamine improves survival after gut ischemia/reperfusion. J Parenter Enteral Nutr. 2002; 26(3):169-173.

52. Zarzaur BL, Ikeda S, Johnson CD, et al. Mucosal immunity preservation with bombesin or glutamine is not dependent on Muscosal Addressin Cell Adhesion Molecule-1 (MAdCAM-1) expression. J Parenter Enteral Nutr. 2002; 26(5):265-270.

53. Roy CC, Kien CL, Bouthillier L, et al. Short-Chain Fatty Acids: Ready for prime time. Nutr Clin Pract. 2006; 21:351-366. [PubMed: 16870803]

54. Topping DL, Clifton PM. Short-chain fatty acids and human colonic function: roles of resistant starch and non starch polysaccharides. Physiol Rev. 2001; 81:1031-1064. [PubMed: 11427691]

Surg Clin North Am. Author manuscript; available in PMC 2012 August 1. 
55. Tungland BC, Meyer D. Nondigestible oligo-and polysaccharides (dietary fiber): their physiology and role in human health and food. Comprehens Rev Food Sci Food Safety. 2002:73-92.

56. McAndrew HF, Lloyd DA, Rintala R, et al. Intravenous glutamine or short-chain fatty acids reduce central venous catheter infection in a model of total parenteral nutrition. J Pediatr Surg. 1999; 34:281-285. [PubMed: 10052805]

57. Murakoshi S, Fukatsu K, Omata J, et al. Effects of adding butyric acid to total parenteral nutrition on gut-associated lymphoid tissue and mucosal immunoglobulin A levels. JPEN J Parenter Enteral Nutr. in press.

58. Fujihashi, K.; Ernst, PB. A mucosal internet, in Mucosal Immunology. Ogra, PL.; Mestecky, J.; Lamm, ME.; Strober, W.; Bienenstock, J.; McGhee, JR., editors. Academic Press; San Diego: 1999. p. 619-630.

59. Yada S, Nukina H, Kishihara K, et al. IL-7 prevents both caspase- dependent and -independent pathways that lead to the spontaneous apoptosis of i-IEL. Cell Immunol. 2001; 208(2):88-95. [PubMed: 11333141]

60. Watanabe M, Ueno Y, Yajima T, et al. Interleukin 7 is produced by human intestinal epithelial cells and regulates the proliferation of intestinal mucosal lymphocytes. J Clin Invest. 1995; 95(6): 2945-2953. [PubMed: 7769137]

61. Yang H, Sun X, Haxhija EQ, et al. Intestinal epithelial cell-derived interleukin-7: A mechanism for the alteration of intraepithelial lymphocytes in a mouse model of total parenteral nutrition. Am $\mathrm{J}$ Physiol Gastrointest Liver Physiol. 2007; 292(1):G84-91. [PubMed: 17215438]

62. Fukatsu K, Moriya T, Maeshima Y, et al. Exogenous IL-7 affects gut associated lymphoid tissue in mice receiving total parenteral nutrition. Shock. 2005; 24(6):541-6. [PubMed: 16317385]

63. Fukatsu K, Moriya T, Ikezawa F, et al. Interleukin-7 dose dependently restores parenteral nutrition-induced gut associated lymphoid tissue cell loss. JPEN J Parenter Enteral Nutr. 2006; 30(5):388-93. [PubMed: 16931606]

64. Nagayoshi H, Fukatsu K, Ueno C, et al. 5-fluorouracil infusion reduces gut-associated lymphoid tissue cell number and mucosal IgA levels. JPEN J Parenter Enteral Nutr. 2005; 29(6):395-400. [PubMed: 16224030]

65. Fukatsu K, Nagayoshi H, Maeshima Y, et al. Fish oil infusion reverses 5-fluorouracil-induced impairments in mucosal immunity in mice. Clin Nutr. 2008; 27(2):269-75. [PubMed: 18249477]

66. Maeshima Y, Fukatsu K, Moriya T, et al. Influence of adding fish oil to parenteral nutrition on gutassociated lymphoid tissue. JPEN J Parenter Enteral Nutr. 2007; 31(5):416-22. [PubMed: 17712151]

67. Hering J, Garrean S, Dekoj TR, et al. Inhibition of proliferation by omega-3 fatty acids in chemoresistant pancreatic cancer cells. Ann Surg Oncol. 2007; 14(12):3620-8. [PubMed: 17896154]

68. Maddaus MA, Ahrenholz D, Simmons RL. The biology of peritonitis and implications for treatment. Surg Clin North Am. 1988; 68:431-443. [PubMed: 3279556]

69. Barnes PJ, Karlin M. NFkB-a pivotal transcription factor in chronic inflammatory diseases. N Eng J Med. 1997; 336:1066-1071.

70. Ueno C, Fukatsu K, Kang WD, et al. Route and type of nutrition influence NFkB activation in peritoneal resident cells. Shock. 2005; 24(4):382-7. [PubMed: 16205325]

71. Ueno C, Fukatsu K, Kang W, et al. Lack of enteral nutrition delays nuclear factor kappa B activation in peritoneal exudative cells in a murine glycogen-induced peritonitis model. JPEN J Parenter Enteral Nutr. 2006; 30(3):179-85. [PubMed: 16639063]

72. Ueno C, Fukatsu K, Maeshima Y, et al. Arginine-enriched total parenteral nutrition improves survival in peritonitis by normalizing NFkB activation in peritoneal resident and exudative leukocytes. Ann Surg. 2010; 251(5):959-65. [PubMed: 20395852]

73. Lin MT, Saito H, Furukawa S, et al. Alanyl-glutamine enriched total parenteral nutrition improves local, systemic, and remote organ responses to intraperitoneal bacterial challenge. JPEN J Parenter Enteral Nutr. 2001; 25(6):346-51. [PubMed: 11688940]

74. Mackay IR. Hepatoimmunology: a perspective. Immunol Cell Biol. 2002; 80:36-44. [PubMed: $11869361]$ 
75. Moriya T, Fukatsu K, Maeshima Y, et al. Nutritional route affects ERK phosphorylation and cytokine production in hepatic mononuclear cells. Ann Surg. 2007; 245(4):642-50. [PubMed: 17414615]

76. Omata J, Fukatsu K, Maeshima Y, et al. Enteral nutrition rapidly reverses total parenteral nutritioninduced impairment of hepatic immunity in a murine model. Clin Nutr. 2009; 28(6):668-73. [PubMed: 19541395]

77. Omata J, Fukatsu K, Murakoshi S, et al. Enteral re-feeding rapidly restores parenteral nutritioninduced reduction of hepatic mononuclear cell number through recovery of small intestine and portal vein blood flows. JPEN J Parenter Enteral Nutr. 2009; 33(6):618-25. [PubMed: 19675300] 


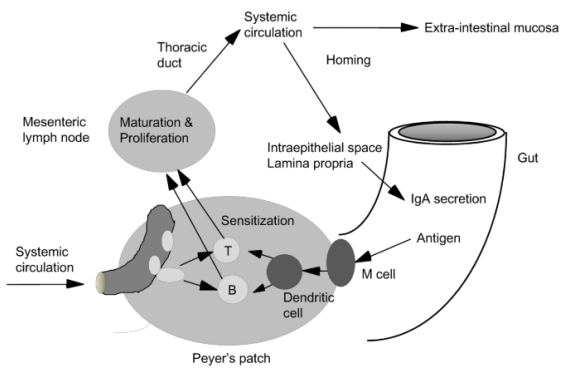

Figure 1. Gut associated lymphoid tissue (GALT) and systemic mucosal immunity GALT is a center of systemic mucosal immunity. Naïve lymphocytes are sensitized at Peyer's patches, migrate to mesenteric lymph nodes, enter to systemic circulation via thoracic duct, and home to mucosal sites. 


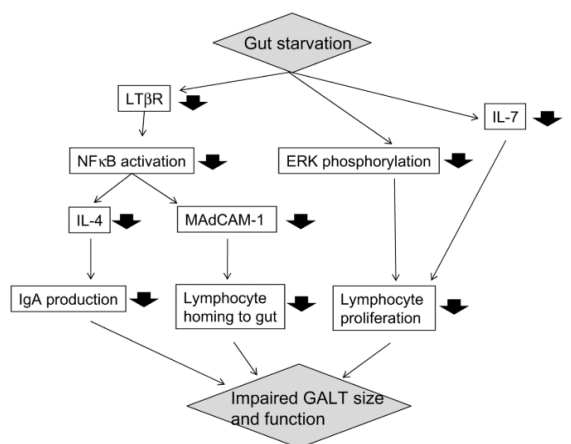

Figure 2. Mechanisms underlying impaired immunity during gut starvation Impairment of gut immunity due to gut starvation is related to reduced LT $\beta R$ expression, ERK phosphorylation, IL-7 production and other factors. 




Figure 3. Influence of gut starvation on peritoneal host defense

Gut starvation blunts NFאB activation in peritoneal resident macrophages and exudative neutrophils, impairing peritoneal host defense against bacterial contamination. 


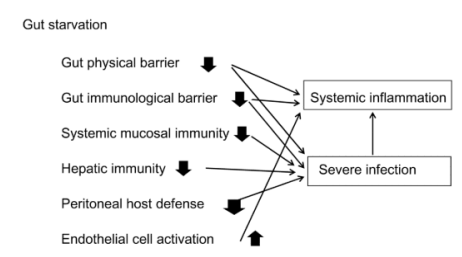

Figure 4. Influences of gut starvation on host immunity and inflammation

Gut starvation impairs various host defense systems, while causing inappropriate activation of endothelial cells. 


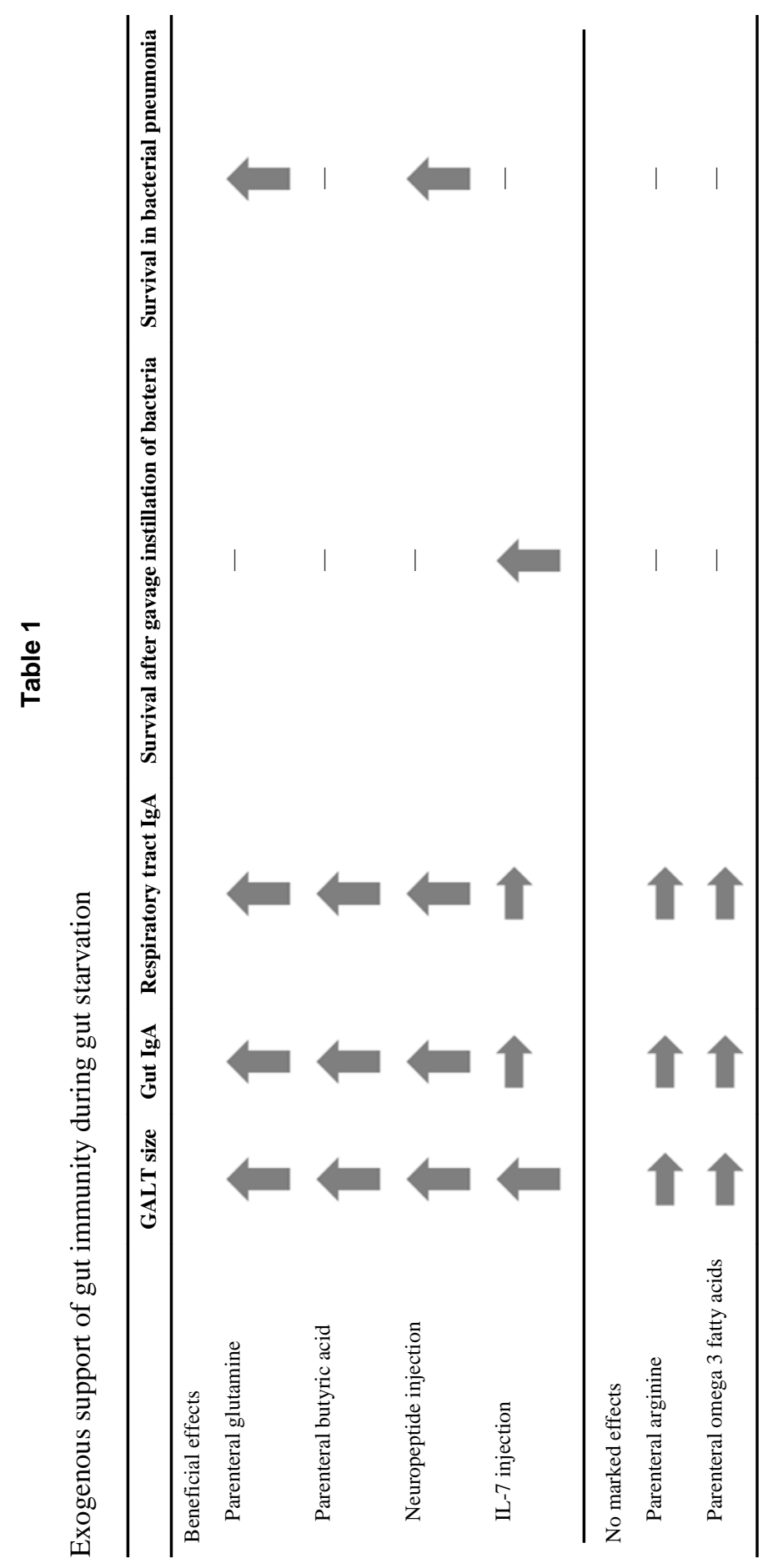

Surg Clin North Am. Author manuscript; available in PMC 2012 August 1. 